\title{
Brominated flame retardants (BFRs) in indoor and outdoor air in a community in Guangzhou, a megacity of southern China
}

\author{
Nan Ding a,b, Tao Wang a,b, She-Jun Chen ${ }^{a *}$, Mei Yu ${ }^{\text {c }}$, Zhi-Cheng Zhu ${ }^{\text {a,b }}$, Mi Tian ${ }^{\text {d }}$, Xiao-Jun \\ Luo $^{\text {a }}$, Bi-Xian Mai ${ }^{\text {a }}$
}

a State Key Laboratory of Organic Geochemistry and Guangdong Key Laboratory of Environmental Protection and Resources Utilization, Guangzhou Institute of Geochemistry, Chinese Academy of Sciences, Guangzhou 510640, China

${ }^{\mathrm{b}}$ University of Chinese Academy of Sciences, Beijing 100049, China

${ }^{c}$ College of Chemical Engineering, Guangdong University of Petrochemical Technology, Maoming, 525000, China

${ }^{\mathrm{d}}$ Key Laboratory of Reservoir Aquatic Environment of CAS, Chongqing Institute of Green and Intelligent Technology, Chinese Academy of Sciences, Chongqing 400714, China

\begin{abstract}
Indoor environments contribute a significant portion of human exposure to brominated flame retardants (BFRs) because of their extensive use in various household products.

This study investigates the occurrence of a number of BFRs in the indoor and outdoor air in a megacity in southern China, in which little information on indoor BFRs
\end{abstract}

* Corresponding author. Tel: +86-20-85291509; fax: +86-20-85290706;

E-mail address: chenshejun@gig.ac.cn (S.J. Chen)

1

C 2016. This manuscript version is made available under the Elsevier user license http://www.elsevier.com/open-access/userlicense/1.0/ 
contamination is available. The estimated total PBDE concentrations ranged from 1.43 to $57 \mathrm{pg} / \mathrm{m}^{3}$ indoors and from 1.21 to $1522 \mathrm{pg} / \mathrm{m}^{3}$ outdoors. The indoor concentrations of lower brominated PBDEs that are mainly derived from the technical penta- and octa-BDE mixtures were higher than or comparable to the outdoors, while the indoor levels of DecaBDEs and decabromodiphenyl ethane (DBDPE) were apparently lower than the outdoors. The seasonal variations of BFR concentrations indicated that evaporation from old indoor products is the primary source of Penta- and OctaBDEs in the air, whereas most DecaBDEs and DBDPE concentrations showing weak temperature-dependence are largely released from industrial activities. The PBDE congener profiles in the air were generally similar, which were dominated by BDE209, 28, and 47; whereas the appreciable indoor-outdoor differences in the compositions are possibly due to emission sources, photochemical degradation, or congener-specific transport of BFRs in the indoor and outdoor air . Significant correlations between the indoor and outdoor BFRs were observed suggesting the exchange of BFRs between the two compartments, which are more noticeable for PentaBDEs and DecaBDEs with strong indoor and outdoor emission sources, respectively. This study provides significant insights into the sources of BFRs in urban air in China.

Key words: Brominated flame retardants (BFRs); Indoor and outdoor air; Source;

Seasonal variation; Southern China

\section{Capsule:}

Indoor environment is a significant sources of restricted PBDEs but DecaBDEs and 
DBDPE are largely derived from industry in southern China.

\section{Introduction}

In the past two decades, there have been growing concerns about brominated flame retardants (BFRs), many of which exhibit persistence and bioaccumulation properties and have been detected globally (Hites, 2004; Hung et al., 2013). BFRs are extensively used in a variety of products in homes and offices such as electronic equipment, furniture, fabrics, car interiors, and construction materials to slow the spread of fire (Batterman et al., 2009). Polybrominated diphenyl ethers (PBDEs) are a class of the most important BFRs, which are manufactured and used in three technical mixtures as penta-, octa-, and deca-BDE and the former two mixtures have been restricted under the Stockholm Convention. With the restriction or voluntary withdrawals of PBDEs, an increasing number of alternate flame retardants, such as bis(2,4,6,-tribromphenoxy)ethane (BTBPE), decabromodiphenyl ethane (DBDPE), and 2-ethylhexyl2,3,4,5-tetrabromobenzoate (TBB), are being introduced in commercial applications (Stapleton et al., 2008). Like PBDEs, these chemicals have been found in various environmental media from different locations in the world (de Wit et al., 2010; Covaci et al., 2011).

Most of BFRs are physically mixed into products and are readily released into the environment (Suzuki et al., 2009). Thus, indoor environments (homes, workplaces, schools, and cars) contribute a significant portion of total human exposure to these chemicals as people spend most (over 90\%) of their time indoors. In recent years, 
considerable attention has been paid to the indoor BFR contamination and associated human exposure. High levels of BFRs have been found in indoor dust in many regions (Besis and Samara, 2012; Zhu et al., 2015), which is considered to be an important medium of exposure to BFRs (Stapleton et al., 2008; Shoeib et al., 2012). A previous study suggests that brominated compounds are transferred from products to dust matrices either through miniaturization and subsequent direct migration into dust as plastic and textile fragments or through vaporization and airborne transfer of microparticulates (Suzuki et al., 2009).

Higher concentrations of BFRs have been measured indoors than outdoors due to the emission of BFRs from indoor electronic equipment and furniture (Wilford et al., 2004; Hazrati and Harrad, 2006). Zhang et al. (2011) estimated the total emissions (87-550 $\mathrm{ng} / \mathrm{h}$ ) of PBDEs from a Toronto office using a Multimedia Indoor Mode. Batterman et al. (2009) found that BFR-containing materials in buildings in the U.S. constitute a large reservoir of these compounds and may be a significant environmental source. The authors estimated that the aggregate emission rate of PBDEs from U.S. houses was $4000 \mathrm{ng} / \mathrm{h}$ per house. Therefore, it is suggested that indoor emission is a significant source of BFRs in the air in European and North American countries, where significant outdoor industrial sources of BFRs are absent because of the transfer of manufacturing industries as well as obsolete products and wastes containing BFRs from developed countries to developing countries (Breivik et al., 2011).

The Pearl River Delta (PRD) is one of the most prosperous regions of China, and many 
previous studies conducted in this region revealed the extensive contamination of BFRs in the environment and biota due to the rapid industrialization and urbanization (Mai et al., 2005; Meng et al., 2007; Guan et al., 2009; Guo et al., 2014). High PBDE concentrations (averaged $2450 \mathrm{pg} / \mathrm{m}^{3}$ ) in the ambient (outdoor) air have been reported in a city in the PRD (Chen et al., 2006), which were much higher than those (50-150 pg/m $\mathrm{m}^{3}$ ) typically observed in urban air in North America, Europe, and other Asian countries (Tian et al., 2011), implying existence of outdoor industrial sources. The PBDEs measured in indoor dust in a few PRD cities were at intermediate levels with means of 2365-6875 ng/g (Huang et al., 2010; Wang et al., 2010; Chen et al., 2014). However, little is known about the BFR contamination in the indoor air in this region, which is possibly different from those in the developed countries because the BFR applications in products may be varied in these regions. It is also unknown how the indoor and outdoor compartments will influence one another in regions where there are emissions of BFRs from industrial activities.

In the present study, indoor and outdoor air samples were collected by passive air sampler (PAS) for more than one year. We aim to investigate and compare the BFR concentrations and composition profiles in the air, to know the seasonal pattern of BFRs in the air, and to explore the potential link between indoor and outdoor compartments in the PRD region, which are very helpful to understand the emission sources of BFRs in the air in many Chinese cities.

\section{Material and methods}




\subsection{Sample collection}

Indoor and outdoor air samples were collected simultaneously in a community in Guangzhou City in the PRD, southern China. Guangzhou has a humid subtropical climate with an average annual temperature of $22.3{ }^{\circ} \mathrm{C}$ in 2013 . It is the largest city in southern China and has a population of approximately 13 million. The sampling site $\left(23^{\circ} 15^{\prime} \mathrm{N}\right.$, $113^{\circ} 36^{\prime} \mathrm{E}$ ) is a representative of the residential areas in Guangzhou without specific BFR point sources nearby. The sampling was conducted using PASs equipped with polyurethane foam disks (14 $\mathrm{cm}$ diameter and $1.3 \mathrm{~cm}$ thick) that has been described elsewhere (Chaemfa et al., 2014). This technique can provide time-integrated sampling and has been applied in many studies on semi-volatile compounds in air (Jaward et al., 2005; Abdallah and Harrad, 2010).

The PASs were deployed in three buildings (designated as A, B, and C) from December 2012 to March 2014 (Fig. S1 in the Supplementary Data). Specifically, the samples were taken from one home in Building A (ninth floor, $90 \mathrm{~m}^{2}$ ), three homes in Building B (fifth floor, $70 \mathrm{~m}^{2}$; fourth floor, $70 \mathrm{~m}^{2}$; and fourth floor, $60 \mathrm{~m}^{2}$ ), and two offices in Building $\mathrm{C}$ (both second floor, $30 \mathrm{~m}^{2}$ ). The PASs were suspended $(2.8 \mathrm{~m}$ above the floor) in living room and open balcony (outside windows for offices) to collect indoor and outdoor air, respectively. They were deployed for approximately 60 days in each sampling session and in total 72 samples (48 indoor samples and 24 outdoor samples) were obtained. Prior to use, the PUF disks were Soxhlet-extracted twice with dichloromethane (DCM) for $72 \mathrm{~h}$ in total and were dried under vacuum. The PUF disks 
were wrapped with aluminum foil and sealed in Teflon bags before and after each sample collection. Three clean PUF disks were used for monitoring possible contamination during collection.

\subsection{Analytical protocols}

PUF samples were Soxhlet extracted with a mixture of hexane and acetone (1:1) for 48 h. BDE77, 181, and 205 were added as surrogates to monitor the recoveries before extraction. The extracts were concentrated to $1 \mathrm{~mL}$ and then eluted through a silica/alumina column with 1:1 hexane-dichloromethane. The eluate was evaporated to dryness and re-dissolved in hexane. BDE118 and 128 were added as quantitation standards.

Sample analysis was carried out using a gas chromatograph coupled to a mass spectrometer in electron capture negative ionization mode (GC-ECNI-MS). Di- through hepta-BDEs, pentabromoethylbenzene (PBEB), pentabromotoluene (PBT), hexabromobenzene (HBB), 2,3,5,6-tetrabromo-p-xylene (pTBX), and polybrominated biphenyl (PBB153) were separated with a DB-XLB $(30 \mathrm{~m} \times 0.25 \mathrm{~mm}$ i.d., $0.25 \mu \mathrm{m}$ film thickness) capillary column. For octa- through deca-BDEs, DBDPE, BTBPT, and PBB209, a DB-5HT (15 m $\times 0.25 \mathrm{~mm}$ i.d., $0.10 \mu \mathrm{m}$ film thickness $)$ column was used. Detailed description on the analytical protocols has been given in a previous study (Tian et al., 2011).

\subsection{Quality Control.}

In field blanks and procedural blanks (clean PUF plugs), only BDE28, 47, and 99 were 
found, but their amounts were all less than $5 \%$ of those in the sample extracts. The concentrations in the samples were blank corrected accordingly. The amounts of PBDEs found in the field blanks were not significantly higher than the procedural blanks. The recoveries of the surrogate standard (mean \pm standard deviation) were $98.2 \pm 19.4 \%$ for BDE77, and 73.2 $\pm 18.6 \%$ for BDE181, and 74.6 $\pm 17.6 \%$ for BDE205. Reported concentrations were not surrogate-recovery corrected. The method detection limits, defined as the mean blank mass plus three standard deviations or a signal five times the noise level, were between 0.14 and $1.31 \mathrm{pg} / \mathrm{m}^{3}$.

\section{Results and discussion}

\subsection{Concentrations}

The air concentrations of BFRs in the present study were estimated based on the average sampling rates of PAS for PBDEs in indoor $\left(1.66 \mathrm{~m}^{3} / \mathrm{d}\right)$ and outdoor $\left(4.78 \mathrm{~m}^{3} / \mathrm{d}\right)$ environments determined in two early studies, respectively (Pozo et al., 2004; Hazrati and Harrad, 2007). The three major technical mixtures of PBDEs have different compositions of congeners. Lower brominated congeners (BDE28, 47, 66, 99, 100, 154, 153, and 138) are derived mainly from the technical penta-BDE mixture (designated as PentaBDEs). The PentaBDE concentrations from the three buildings ranged from 1.43 to $30.8 \mathrm{pg} / \mathrm{m}^{3}$ in the indoor air and from 1.07 to $15.3 \mathrm{pg} / \mathrm{m}^{3}$ in the outdoor air (Table 1). There was no statistically significant difference between the indoor and outdoor air ( $p=0.579, t$-test), with medians of 4.64 and $4.63 \mathrm{pg} / \mathrm{m}^{3}$, respectively. The concentrations of intermediate congeners (OctaBDEs, including BDE183, 196, 197, 202, and 203), main components of 
the technical octa-BDE mixture, were lower than the levels of PentaBDEs, consistent with previous results in the PRD (Mai et al., 2005; Wang et al., 2010). The outdoor levels $\left(\right.$ median $\left.=2.44 \mathrm{pg} / \mathrm{m}^{3}\right)$ were a little higher than indoors $\left(1.46 \mathrm{pg} / \mathrm{m}^{3}\right)$, whereas several outliers $\left(8.91-20.0 \mathrm{pg} / \mathrm{m}^{3}\right)$ were found in the indoor samples.

Although the PAS largely collects the gaseous phase, the concentrations of highly brominated compounds in the air, which are predominantly particle-bound due to very low vapor pressures, were 1-2 orders of magnitude higher than the PentaBDE levels. The concentrations of BDE206, 207, 208, and 209 (DecaBDEs), which constitute the majority of the technical deca-BDE mixture, were significantly higher outdoors than indoors with medians of 454 and $69.6 \mathrm{pg} / \mathrm{m}^{3}$, respectively ( $\mathrm{p}<0.001$ ). DBDPE is a novel alternative BFR with high molecular weight also showed apparently higher outdoor concentrations $\left(\right.$ median $\left.=127 \mathrm{pg} / \mathrm{m}^{3}\right)$ than indoors $\left(74.9 \mathrm{pg} / \mathrm{m}^{3}\right)$, although the difference is not statistically significant. This is because airborne fine or ultrafine particles can penetrate the sampling chamber and are collected on the PUF disk (Klanova et al., 2008). In addition, technical DecaBDEs and DBDPE are being used in large quantities in China (Chen et al., 2013) and consequently are present at higher levels in the environment. The indoor-outdoor differences for DecaBDEs and DBDPE are inconsistent with those found in a recent study in Stockholm, Sweden, where the indoor concentrations (medians $=12$ and $130 \mathrm{pg} / \mathrm{m}^{3}$ ) were much higher than outdoors (medians $=0.15$ and $0.18 \mathrm{pg} / \mathrm{m}^{3}$ ) (Newton et al., 2015). The contamination of DecaBDEs and DBDPE in the southern China air implied presence of significant outdoor sources. These chemicals probably 
release from the great number of industrial zones distributed across Guangzhou and spread over the city. The levels and detection frequencies of other target BFRs (BTBPE, PBBs, PBT, PBEB, and pTBX) were very low and, therefore, not discussed here.

We observed higher concentrations of PentaBDEs, with geometric means (GMs) of $9.26 \mathrm{pg} / \mathrm{m}^{3}$, in the home of Building A than homes in Buildings B and C (4.77 and 5.21 $\mathrm{pg} / \mathrm{m}^{3}$, respectively); while the concentrations of other BFRs in the three buildings were comparable (Fig. S2). This result indicated a stronger indoor source of PentaBDEs in homes of Building A probably due to the elder household products. People moved into Building A around 2000, while the move to Buildings B and C took place in 2009. In 2007, PBDEs that are largely from technical penta- and octa-BDE mixtures were banned in China leading to significant reduction in their use in relevant products and consequently the emissions from household products. This finding is in agreement with a previous observation that the air PBDE concentrations in an office in Birmingham, UK declined $80 \%$ after an old computer was replaced with a new one (Hazrati and Harrad, 2006). As ventilation facilities are rarely used for residential buildings and houses in China, the differences in the indoor air PBDE levels in the three buildings may also be attributed to housing characteristics. The structures of Buildings B and C facilitate air exchange between indoor and outdoor environments via open windows, declining the air levels of pollutants releasing indoors.

The PBDE concentrations in the outdoor air were substantially lower than the levels in Guangzhou air measured in 2004, with GMs of $243 \mathrm{pg} / \mathrm{m}^{3}$ for PentaBDEs and $580 \mathrm{pg} / \mathrm{m}^{3}$ 
for DecaBDEs (Chen et al. 2006). In the previous study PBDEs in both gas and total suspended particles were measured, while in the present study, only a small fraction of particles were collected and analyzed. This could be one reason for the lower PBDE concentrations found in the current air. However, the phase-out of PBDEs (with the exception of deca-BDE) in China may be the main reason for the significant reduction of PBDE levels in Guangzhou air, especially for the lower brominated BDEs.

High indoor levels of lower brominated BDEs that are mainly from technical pentaBDE mixture have been reported from Canada (median $=100 \mathrm{pg} / \mathrm{m}^{3}$ ) (Wilford et al., 2004), the U.S. (760 pg/m³) (Johnson-Restrepo and Kannan, 2009), and some European countries $\left(\right.$ medians $=58-4000$ pg/m $\left.\mathrm{m}^{3}\right)($ Harrad et al., 2004; Batterman et al., 2010; Vorkamp et al., 2011; Zhang et al., 2011; Thuresson et al., 2012). Although different sampling methods (active low-volume air sampler or PAS) may cause differences in the measurements, these values were obviously higher than the indoor levels in this study. Our indoor results were also lower than those in Germany $\left(\right.$ median $=37.8 \mathrm{pg} / \mathrm{m}^{3}$ ) and Australia $\left(18 \mathrm{pg} / \mathrm{m}^{3}\right)$ and were comparable to that only in Kuwait $\left(8.2-8.6 \mathrm{pg} / \mathrm{m}^{3}\right)(\mathrm{Gevao}$ et al., 2006; Fromme et al., 2009; Toms et al., 2009). Furthermore, in most of these regions, the indoor PBDE levels in workplaces were much higher than residential levels, whereas in our study the PBDE levels in offices are comparable to or lower than those in homes. This result implied that PBDEs are probably used much less frequently in workplaces in China than other countries and that people will be exposed to more PBDEs in workplaces in these regions than in China. 
Currently, limited information on indoor air contamination of DecaBDEs can be found. The indoor air levels of DecaBDEs reported from other countries (medians $<42 \mathrm{pg} / \mathrm{m}^{3}$ ) (Fromme et al., 2009; Johnson-Restrepo and Kannan, 2009; Batterman et al., 2010; Bjorklund et al., 2012) were much lower than the levels in the present study, except that higher concentrations (medians $=130-3800 \mathrm{pg} / \mathrm{m}^{3}$ ) were found in Sweden (especially in offices and daycare centers) (Bjorklund et al., 2012; Thuresson et al., 2012). The substantially lower indoor air levels PBDEs (except for DecaBDEs) in the present study were probably attributed to less rigorous fire prevention standard in China than in North America and Europe, which results in the small use of BFRs in indoor products and lower emission from the products.

\subsection{Compositions}

The congener profiles of lower brominated BDEs in the indoor and outdoor air were generally similar suggesting a common source for them (Fig. 1). These PBDEs were dominated by BDE28, 47, and 99 collectively accounting for $75.1-85.3 \%$ of the PentaBDEs. The profiles were not similar to the compositions in the technical penta-BDE mixtures, in which BDE99 (42.0\%) and BDE47 (36.6\%) are predominant (La Guardia et al., 2006). This is because less brominated congeners have higher vapor pressures and are more prone to evaporate from products. This is supported by the contributions of BDE28 and 47 in the indoor and outdoor air. The contributions of BDE28 exceeded those of BDE47 in the indoor air, while BDE47 showed noticeably higher contributions than BDE28 in most outdoor air. This difference, however, could also arise from congener- 
specific migration behaviors from indoors to outdoors and/or photochemical degradation of PBDEs outdoors. Raff and Hites (2007) found that photolysis is responsible for most of the removal of gas-phase PBDEs from the atmosphere.

The congener profiles of highly brominated BDEs were significantly similar in respective indoor and outdoor air than between them, with BDE209 comprising over $88.4 \%$ of them (Fig. 1). It was found that the contributions of nona-BDEs were higher indoors than outdoors, and the indoor profiles were closer to those in the technical products (La Guardia et al., 2006). Because of the low vapor pressures, nona- and decaBDEs are associated predominantly with particles. The indoor-outdoor difference was not likely a result of photolytic processes in the outdoor air, as particle-bound PBDEs are much less susceptible to photodegradation especially in urban carbonaceous aerosols (Raff and Hites, 2007). The difference may be due to different behaviors in the process of migration of these congeners from outdoors to indoors. Alternatively, the disparities in the profiles could be a result of variations of congener-specific passive sampling rates between indoors and outdoors because of different temperature and wind speed in the two environmental compartments (Klanova et al., 2008). To our knowledge, no studies have been conducted to investigate the influence of these meteorological parameters on congener-specific sampling rates of PBDEs. A study investigating the wind effect on polychlorinated biphenyls (PCBs) in the laboratory found that the influence was more pronounced for highly chlorinated congeners than for low chlorinated PCBs as air velocity increased (Tuduri et al., 2006). 
The ratios of DBDPE/DecaBDEs in the air were also compared, since DBDPE is a major replacement of deca-BDE product. In the indoor air, the ratios exceeded one in $50 \%$ of the samples (median $=0.95)$; while in the outdoor air, the ratios are less than one in $90 \%$ of the samples (median $=0.38)$. Although potential differences in indoor-outdoor sampling rates and migration behaviors for these two compounds possibly influence the ratios, such remarkable indoor-outdoor differences were likely indicative of more robust outdoor sources of DecaBDEs than DBDPE to the air in the study area.

\subsection{Seasonal variations and correlations}

The seasonal variations of BFR concentrations in the air and of the monthly average ambient outdoor temperature $\left(13.3-28.5^{\circ} \mathrm{C}\right)$ were depicted in Fig. S3 and only those for Building B were shown in Fig. 2. It is interesting that the concentrations of PentaBDEs showed similar temporal variations to the ambient temperature in all the indoor and outdoor environments. This clearly indicated that these PBDEs, with higher vapor pressures, were strongly controlled by temperature-driven evaporation from indoor products and/or construction materials. The concentrations of OctaBDEs showed significantly or moderately temperature-dependence, suggesting a similar emission mechanism to the PentaBDEs. However, it could not be ruled out that part of PBDEs in the air may be derived from evaporation from contaminated surfaces (e.g., soils, water, or plants) around the sampling location. It is expected that the temperature-dependence of air concentrations of DecaBDEs and DBDPE was much less significant given their low vapor pressures. Moderate temperature-dependence was observed only for a few indoor 
environments. The finding confirmed the primary industrial sources of these two BFRs in the air in the study region.

Pearson correlation analysis among the BFR concentrations (log-normalized) was conducted for indoor and outdoor air, respectively (Fig. S4). Correlations for the indoor air BFR concentrations showed that there were significant correlations among PentaBDEs, OctaBDEs, and DBDPE $(r=0.528-0.670, p<0.002)$. The significant correlations between penta-BDE and DBDPE is surprising considering their applications in different types of products (furniture and electronic equipment, respectively) and physicochemical properties. The result may suggest the existence of indoor sources of DBPDE as well as a generally similar influence on the indoor BFR contamination. However, the influencing factors are unknown and merit further investigation. There were no significant correlations between Penta- or OctaBDEs and DecaBDEs, but DBDPE showed significant relationships with DecaBDEs $(r=0.491, p=0.001)$.

In the outdoor air, significant correlations were also found for the concentrations of PentaBDEs, OctaBDEs, and DBDPE $(r=0.470-0.680, p<0.003)$, while they did not show significant correlations with DecaBDE levels. The likely explanation is that there are strong outdoor emissions of DecaBDEs such as from industry affecting their correlations. The high outdoor-indoor ratios and weak temperature-dependence compared to other BFRs supported this hypothesis.

Correlations analysis was also conducted between the indoor and outdoor BFR levels (Fig. 3). Interestingly, the correlations were most significant for penta-BDEs $(r=0.536, p$ 
$=0.007)$, followed by those for deca-BDEs $(r=0.521, p=0.019)$, octa-BDEs $(r=0.468$, $p=0.024)$, and DBDPE $(r=0.439, p=0.046)$. These correlations were likely a reflection of the interactions between the indoor and outdoor compartments for the BFRs. The indoor and outdoor concentrations indicated strong indoor sources for PentaBDEs and outdoor sources for DecaBDEs compared to OctaBDEs and DBDPE in our study area.

Thus, PentaBDEs and DecaBDEs may exert a more significant influence on the opposite compartments than the other two classes of BFRs do, and showed more significant indoor-outdoor correlations.

\section{Implications and conclusions}

This study investigated the occurrence of a number of BFRs in the indoor and outdoor air in a megacity in southern China with rapid economic development. We observed much lower indoor levels of PentaBDEs and considerably smaller indoor-outdoor difference compared to developed countries because of the less rigorous fire prevention standard and legislative restrictions of these PBDEs in China. Emissions from indoor products manufactured before 2007 are the primary source of Penta- and OctaBDEs in the air and the processes are temperature-dependent. DecaBDEs and DBDPE showed apparently higher outdoor concentrations are largely released from industrial activities. The significant correlations between the indoor and outdoor BFRs suggest the interactions between the two compartments, which are more noticeable for PentaBDEs and DecaBDEs. The differences in the PBDE congener profiles are possibly due to emission sources, photochemical degradation, or congener-specific transport between 
indoors and outdoors.

Current study provides significant insights into the sources of BFRs in the indoor and outdoor air in China. Nevertheless, it is insufficient for elucidating the factors influencing the indoor-outdoor differences in PBDE congener profiles as well as the correlations between some BFRs, which need further research. Further research is also warranted to estimate the inventory and emissions of banned PBDEs in products and the emissions of current-use BFRs from industry in the city.

The findings implied that the overall health risks of exposure to PBDEs via inhalation are lower for Chinese than for North American and European populations because of the substantially (more than one order of magnitude) lower indoor levels and people's long time spent indoors. However, indoor and outdoor air levels of some currently-used or emerging FRs are expected to be high in many Chinese cities compared to developed countries because of China's dominance in global manufacturing, raising concern about human exposure to emerging flame retardants.

\section{Acknowledgments}

This study was financially supported by the National Science Foundation of China (Nos. 41273115 and 41230639) and the Science and Technology Project of Guangdong Province, China (2014B030301060). This is contribution No. IS-2800 from GIGCAS.

\section{References}

Abdallah, M.A.E., Harrad, S., 2010. Modification and calibration of a passive air sampler for monitoring vapor and particulate phase brominated flame retardants in indoor air: Application to car interiors. Environ. Sci. Technol. 44, 3059-3065. 
Batterman, S., Godwin, C., Chernyak, S., Jia, C., Charles, S., 2010. Brominated flame retardants in offices in Michigan, U.S.A. Environ. Intern. 36, 548-556.

Batterman, S.A., Chernyak, S., Jia, C., Godwin, C., Charles, S., 2009. Concentrations and emissions of polybrominated diphenyl ethers from U.S. houses and garages. Environ. Sci. Technol. 43, 2693-700.

Besis, A., Samara, C., 2012. Polybrominated diphenyl ethers (PBDEs) in the indoor and outdoor environments - A review on occurrence and human exposure. Environ. Pollut. $169,217-229$.

Bjorklund, J.A., Thuresson, K., Cousins, A.P., Sellstrom, U., Emenius, G., de Wit, C.A., 2012. Indoor air is a significant source of tri-decabrominated diphenyl ethers to outdoor air via ventilation systems. Environ. Sci. Technol. 46, 5876-5884.

Breivik, K., Gioia, R., Chakraborty, P., Zhang, G., Jones, K.C., 2011. Are reductions in industrial organic contaminants emissions in rich countries achieved partly by export of toxic wastes? Environ. Sci. Technol. 45, 9154-9160.

Breivik, K., Gioia, R., Chakraborty, P., Zhang, G., Jones, K.C., 2011. Are reductions in industrial organic contaminants emissions in rich countries achieved partly by export of toxic wastes? Environ. Sci. Technol. 45, 9154-9160.

Chaemfa, C., Xu, Y., Li, J., Chakraborty, P., Syed, J.H., Malik, R.N., Wang, Y., Tian, C.G., Zhang, G., Jones, K.C., 2014. Screening of atmospheric short- and mediumchain chlorinated paraffins in India and Pakistan using polyurethane foam based passive air sampler. Environ. Sci. Technol. 48, 4799-4808.

Chen, L.G., Mai, B.X., Bi, X.H., Chen, S.J., Wang, X.M., Ran, Y., Luo, X.J., Sheng, G.Y., Fu, J.M., Zeng, E.Y., 2006. Concentration levels, compositional profiles, and gasparticle partitioning of polybrominated diphenyl ethers in the atmosphere of an urban city in South China. Environ. Sci. Technol. 40, 1190-1196.

Chen, S.J., Ding, N., Zhu, Z.C., Tian, M., Luo, X.J., Mai, B.X., 2014. Sources of halogenated brominated retardants in house dust in an industrial city in southern China and associated human exposure. Environ. Res. 135, 190-195.

Chen, S.J., Feng, A.H., He, M.J., Chen, M.Y., Luo, X.J., Mai, B.X., 2013. Current levels and composition profiles of PBDEs and alternative flame retardants in surface sediments from the Pearl River Delta, southern China: Comparison with historical data. Sci. Total Environ. 444, 205-211. 
Covaci, A., Harrad, S., Abdallah, M.A.-E., Ali, N., Law, R.J., Herzke, D., Wit, C.A.d., 2011. Novel brominated flame retardants: A review of their analysis, environmental fate and behaviour. Environ. Intern. 37, 532-556.

de Wit, C.A., Herzke, D., Vorkamp, K., 2010. Brominated flame retardants in the Arctic environment - trends and new candidates. Sci. Total Environ. 408, 2885-2918.

Fromme, H., Korner, W., Shahin, N., Wanner, A., Albrecht, M., Boehmer, S., Parlar, H., Mayer, R., Liebl, B., Bolte, G., 2009. Human exposure to polybrominated diphenyl ethers (PBDE), as evidenced by data from a duplicate diet study, indoor air, house dust, and biomonitoring in Germany. Environ. Intern. 35, 1125-35.

Gevao, B., Al-Bahloul, M., Al-Ghadban, A.N., Ali, L., Al-Omair, A., Helaleh, M., AlMatrouk, K., Zafar, J., 2006. Polybrominated diphenyl ethers in indoor air in Kuwait: Implications for human exposure. Atmos. Environ. 40, 1419-1426.

Guan, Y.F., Sojinu, O.S.S., Li, S.M., Zeng, E.Y., 2009. Fate of polybrominated diphenyl ethers in the environment of the Pearl River Estuary, South China. Environ. Pollut. $157,2166-2172$.

Guo, L.C., Bao, L.J., Wu, F.C., Yue, Q., Zeng, E.Y., 2014. Seasonal deposition fluxes and removal efficiency of atmospheric polybrominated diphenyl ethers in a large urban center: Importance of natural and anthropogenic factors. Environ. Sci. Technol. 48, 11196-11203.

Harrad, S., Wijesekera, R., Hunter, S., Halliwell, C., Baker, R., 2004. Preliminary assessment of UK human dietary and inhalation exposure to polybrominated diphenyl ethers. Environ. Sci. Technol. 38, 2345-2350.

Hazrati, S., Harrad, S., 2006. Causes of variability in concentrations of polychlorinated biphenyls and polybrominated diphenyl ethers in indoor air. Environ. Sci. Technol. 40, 7584-7589.

Hazrati, S., Harrad, S., 2007. Calibration of polyurethane foam (PUF) disk passive air samplers for quantitative measurement of polychlorinated biphenyls (PCBs) and polybrominated diphenyl ethers (PBDEs): Factors influencing sampling rates. Chemosphere 67, 448-455.

Hites, R.A., 2004. Polybrominated diphenyl ethers in the environment and in people: A meta-analysis of concentrations. Environ. Sci. Technol. 38, 945-956. 
Huang, Y.M., Chen, L.G., Peng, X.C., Xu, Z.C., Ye, Z.X., 2010. PBDEs in indoor dust in South-Central China: Characteristics and implications. Chemosphere 78, 169-174.

Hung, H., MacLeod, M., Guardans, R., Scheringer, M., Barra, R., Hamer, T., Zhang, G., 2013. Toward the next generation of air quality monitoring: Persistent organic pollutants. Atmos. Environ. 80, 591-598.

Jaward, F.M., Zhang, G., Nam, J.J., Sweetman, A.J., Obbard, J.P., Kobara, Y., Jones, K.C., 2005. Passive air sampling of polychlorinated biphenyls, organochlorine compounds, and polybrominated diphenyl ethers across Asia. Environ. Sci. Technol. $39,8638-45$.

Johnson-Restrepo, B., Kannan, K., 2009. An assessment of sources and pathways of human exposure to polybrominated diphenyl ethers in the United States. Chemosphere 76, 542-548.

Klanova, J., Eupr, P., Kohoutek, J., Harner, T., 2008. Assessing the influence of meteorological parameters on the performance of polyurethane foam-based passive air samplers. Environ. Sci. Technol. 42, 550-555.

La Guardia, M.J., Hale, R.C., Harvey, E., 2006. Detailed polybrominated diphenyl ether (PBDE) congener composition of the widely used penta-, octa-, and deca-PBDE technical flame-retardant mixtures. Environ. Sci. Technol. 40, 6247-6254.

Mai, B.X., Chen, S.J., Luo, X.J., Chen, L.G., Yang, Q.S., Sheng, G.Y., Peng, P.A., Fu, J.M., Zeng, E.Y., 2005. Distribution of polybrominated diphenyl ethers in sediments of the Pearl River Delta and adjacent South China Sea. Environ. Sci. Technol. 39, 3521-3527.

Meng, X.Z., Zeng, E.Y., Yu, L.P., Guo, Y., Mai, B.X., 2007. Assessment of human exposure to polybrominated diphenyl ethers in China via fish consumption and inhalation. Environ. Sci. Technol. 41, 4882-4887.

Newton, S., Sellstrom, U., de Wit, C.A., 2015. Emerging flame retardants, PBDEs, and HBCDDs in indoor and outdoor media in Stockholm, Sweden. Environ. Sci. Technol. 49, 2912-2920.

Pozo, K., Harner, T., Shoeib, M., Urrutia, R., Barra, R., Parra, O., Focardi, S., 2004. Passive-sampler derived air concentrations of persistent organic pollutants on a northsouth transect in Chile. Environ. Sci. Technol. 38, 6529-6537. 
Raff, J.D., Hites, R.A., 2007. Deposition versus photochemical removal of PBDEs from Lake Superior air. Environ. Sci. Technol. 41, 6725-6731.

Shoeib, M., Harner, T., Webster, G.M., Sverko, E., Cheng, Y., 2012. Legacy and currentuse flame retardants in house dust from Vancouver, Canada. Environ. Pollut. 169, $175-182$.

Stapleton, H.M., Allen, J.G., Kelly, S.M., Konstantinov, A., Klosterhaus, S., Watkins, D., McClean, M.D., Webster, T.F., 2008. Alternate and new brominated flame retardants detected in U.S. house dust. Environ. Sci. Technol. 42, 6910-6916.

Suzuki, G., Kida, A., Sakai, S., Takigami, H., 2009. Existence state of bromine as an indicator of the source of brominated flame retardants in indoor dust. Environ. Sci. Technol. 43, 1437-42.

Thuresson, K., Bjorklund, J.A., de Wit, C.A., 2012. Tri-decabrominated diphenyl ethers and hexabromocyclododecane in indoor air and dust from Stockholm microenvironments 1: Levels and profiles. Sci. Total Environ. 414, 713-721.

Tian, M., Chen, S.J., Wang, J., Zheng, X.B., Luo, X.J., Mai, B.X., 2011. Brominated flame retardants in the atmosphere of e-waste and rural sites in southern China: Seasonal variation, temperature dependence, and gas-particle partitioning. Environ. Sci. Technol. 45, 8819-8825.

Toms, L.M.L., Bartkow, M.E., Symons, R., Paepke, O., Mueller, J.F., 2009. Assessment of polybrominated diphenyl ethers (PBDEs) in samples collected from indoor environments in South East Queensland, Australia. Chemosphere 76, 173-178.

Tuduri, L., Harner, T., Hung, H., 2006. Polyurethane foam (PUF) disks passive air samplers: Wind effect on sampling rates. Environ. Pollut. 144, 377-383.

Vorkamp, K., Thomsen, M., Frederiksen, M., Pedersen, M., Knudsen, L.E., 2011. Polybrominated diphenyl ethers (PBDEs) in the indoor environment and associations with prenatal exposure. Environ. Intern. 37, 1-10.

Wang, J., Ma, Y.J., Chen, S.J., Tian, M., Luo, X.J., Mai, B.X., 2010. Brominated flame retardants in house dust from e-waste recycling and urban areas in South China: Implications on human exposure. Environ. Intern. 36, 535-541.

Wilford, B.H., Harner, T., Zhu, J., Shoeib, M., Jones, K.C., 2004. Passive sampling survey of polybrominated diphenyl ether flame retardants in indoor and outdoor air in 
Ottawa, Canada: implications for sources and exposure. Environ. Sci. Technol. 38, 5312-8.

Zhang, X.M., Diamond, M.L., Robson, M., Harrad, S., 2011. Sources, emissions, and fate of polybrominated diphenyl ethers and polychlorinated biphenyls indoors in Toronto, Canada. Environ. Sci. Technol. 45, 3268-3274.

Zhu, N.Z., Liu, L.Y., Ma, W.L., Li, W.L., Song, W.W., Qi, H., Li, Y.F., 2015.

Polybrominated diphenyl ethers (PBDEs) in the indoor dust in China: Levels, spatial distribution and human exposure. Ecotoxicol. Environ. Saf. 111, 1-8.

\section{Figure captions}

Fig. 1 BFR compositions in the indoor and outdoor air: congener profiles of the lower brominated BDEs (A), congener profiles of the highly brominated BDEs (B), and ratios of DBDPE to DecaBDE (C). Error bars represent standard deviations.

Fig. 2 Seasonal variations of BFR concentrations in the indoor and outdoor air from Building B. Note change of scale. S1-S8 represent the sampling sessions of Dec-Feb, Feb-Mar, Mar-May, May-Jul, Jul-Sep, Sep-Nov, Nov-Jan, and Jan-Mar, respectively. The curves are the average outdoor temperature in each sampling session.

Fig. 3 Pearson correlations between the indoor and outdoor air BFR concentrations from the three buildings. 
Fig. 1
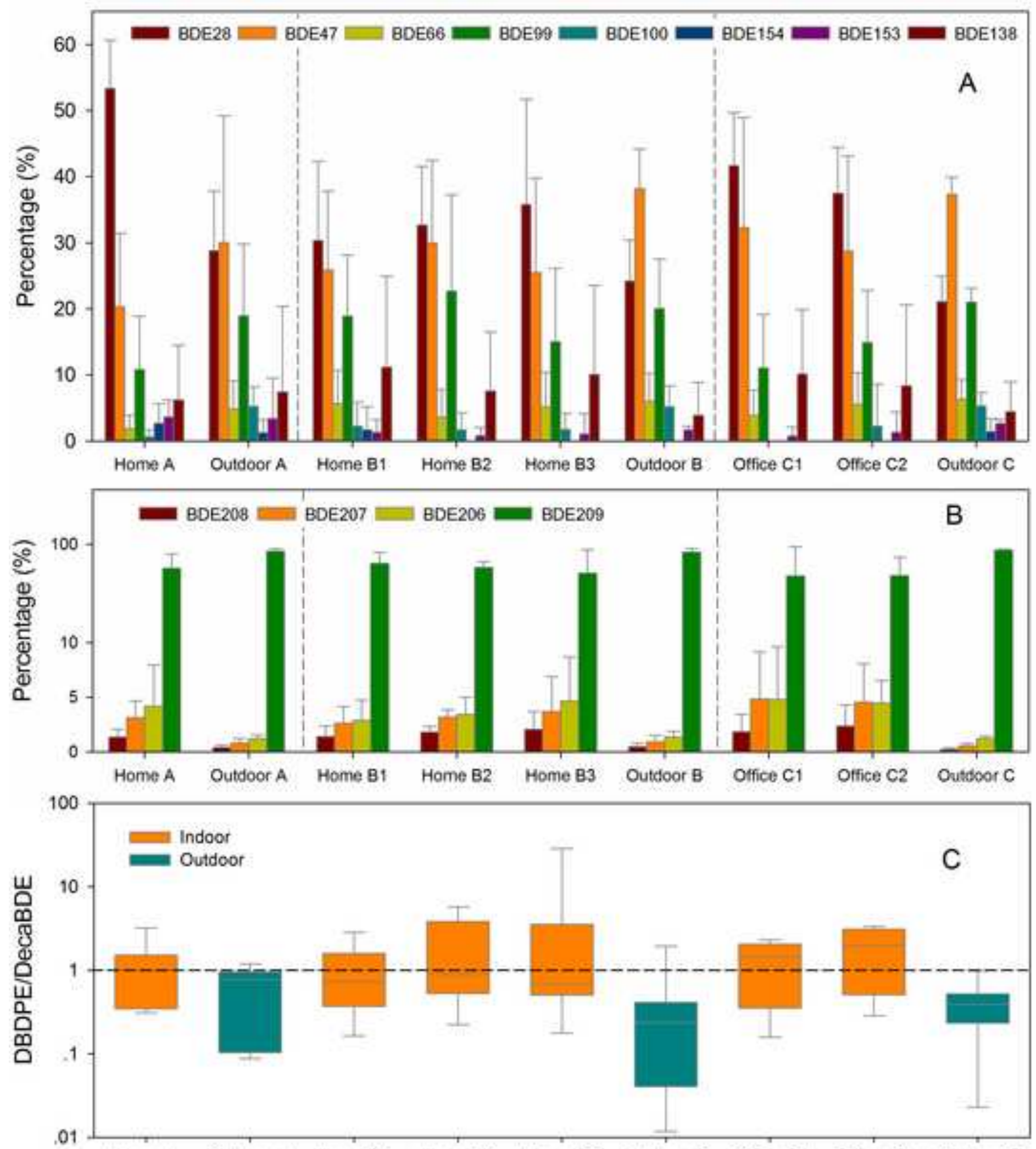

Home A Outdoor A Home B1 Home B2 Home B3 Outdoor B Office C1 Office C2 Outdoor C 

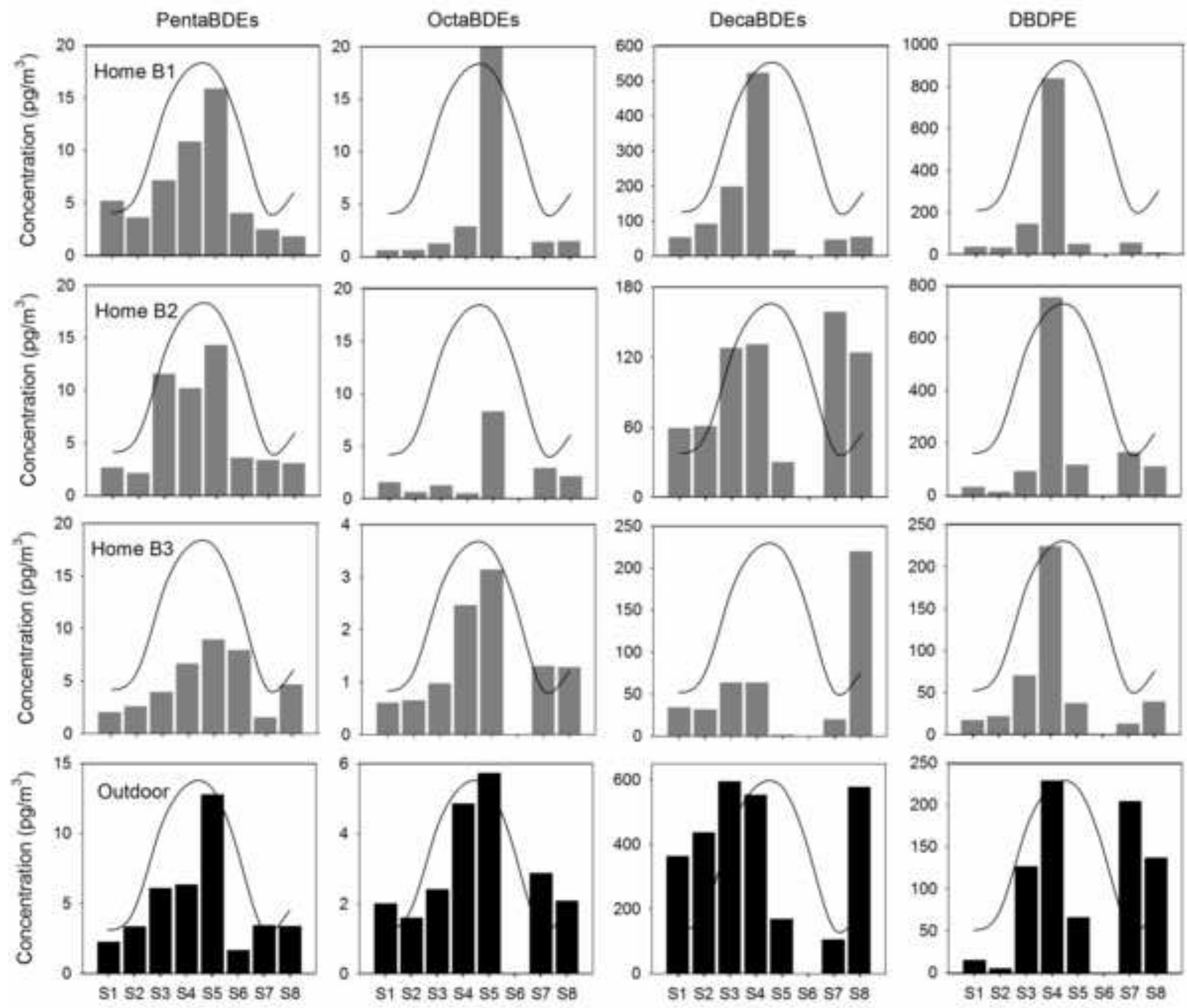

Sampling session 

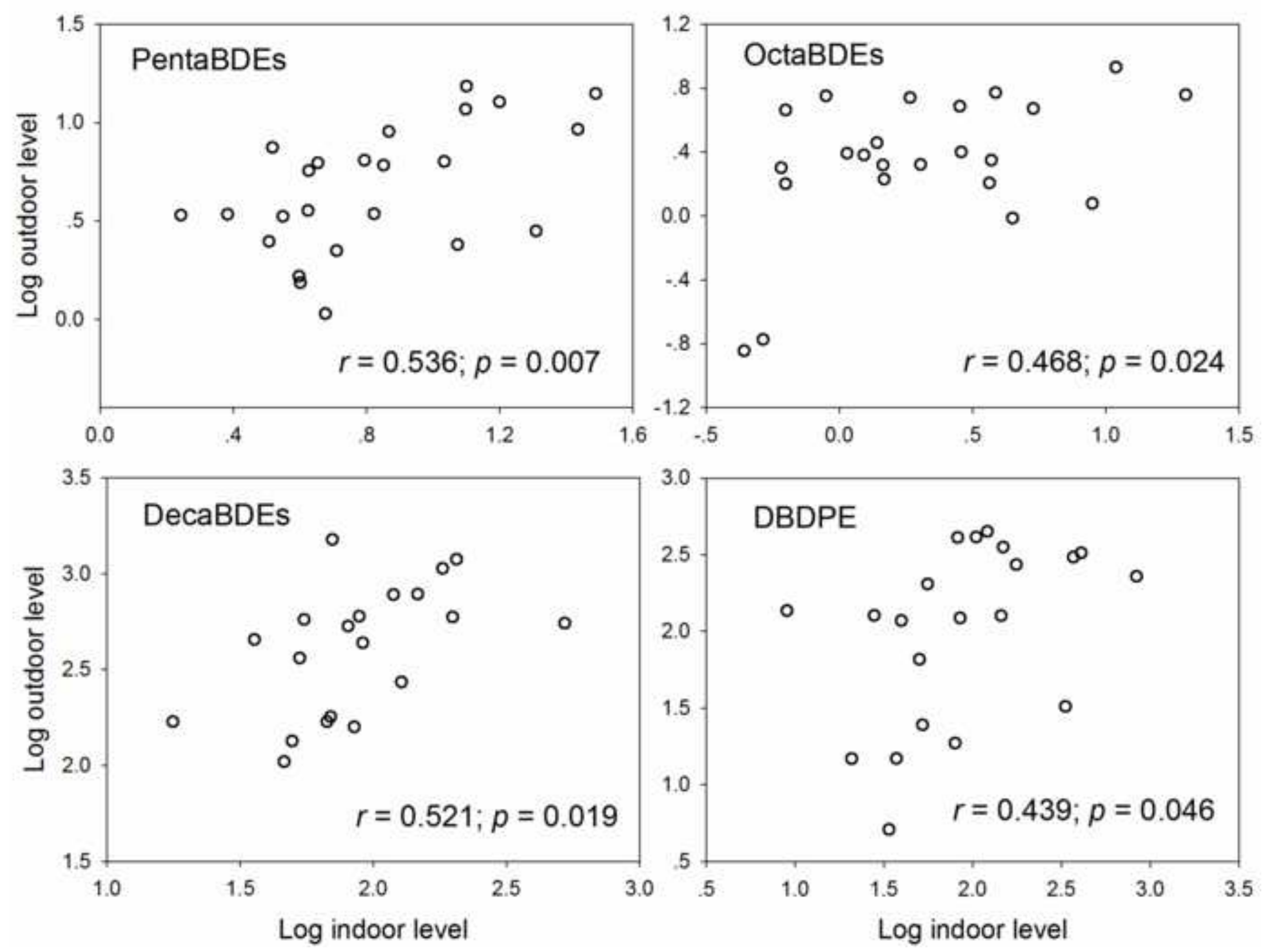
Table 1. Estimated BFR concentrations (median and range, $\mathrm{pg} / \mathrm{m}^{3}$ ) in the indoor air in three buildings (A, B, and $\mathrm{C}$ ) and corresponding outdoor air in a community in Guangzhou, southern China

\begin{tabular}{lccccc}
\hline Microenvironment & PentaBDEs & OctaBDEs & DecaBDEs & PBDEs & DBDPE \\
\hline Home A_I & $8.30(3.21-30.8)$ & $3.66($ n.d.-8.91) & $80.4(49.5-219)$ & $84.0(5.19-255)$ & $79.7(20.8-409)$ \\
Home A_O & $2.65(1.07-14.1)$ & $1.65($ n.d.-2.47) & $169(34.0-533)$ & $169(1.21-538)$ & $117(14.8-325)$ \\
Home B1_I & $4.54(1.75-15.8)$ & $1.38($ n.d.-20.0) & $55.0(17.7-523)$ & $58.4(3.95-537)$ & $50.1(9.00-837)$ \\
Home B2_I & $3.46(2.10-14.3)$ & $1.55($ n.d.-8.29) & $124(30.1-159)$ & $96.3(3.57-165)$ & $110(13.6-754)$ \\
Home B3_I & $4.29(1.52-8.93)$ & $1.28($ n.d.-3.14) & $33.5(1.31-220)$ & $35.5(7.93-226)$ & $37.4(12.6-224)$ \\
Home B_O & $3.40(1.66-12.8)$ & $2.41(1.58-5.73)$ & $436(105-595)$ & $404(1.66-603)$ & $127(5.11-228)$ \\
Office C1_I & $3.83(1.43-12.0)$ & $1.10($ n.d.-6.53) & $54.4(13.6-115)$ & $45.1(1.43-118)$ & $22.1(18.2-181)$ \\
Office C2_I & $6.43(3.29-12.6)$ & 2.87 (n.d.-10.9) & $119(35.8-205)$ & $114(6.65-215)$ & $121(52.2-369)$ \\
Office C_O & $6.96(3.44-15.3)$ & $5.50(2.51-8.53)$ & $784(454-1511)$ & $785(3.44-1522)$ & $355(24.6-449)$ \\
Indoor & $4.64(1.43-30.8)$ & $1.46($ n.d.-20.0) & $69.6(1.31-523)$ & $68.5(1.43-537)$ & $74.9(9.00-837)$ \\
Outdoor & $4.63(1.07-15.3)$ & 2.44 (n.d.-8.53) & $454(34.0-1511)$ & $404(1.21-1522)$ & $127(5.11-449)$ \\
\hline
\end{tabular}

